\title{
O ICMS e o fenômeno da repercussão frente ao consumidor
}

\author{
Luana Michelle da Silva Godoy ${ }^{1}$ \\ Suellen Namiuchi Moriya ${ }^{2}$
}

\begin{abstract}
Resumo
Verifica a necessidade de transparência do ICMS nos produtos e serviços diante do Fenômeno da Repercussão e da conseqüente transferência da carga tributária ao consumidor. Conclui que a transparência do ICMS embutido no produto e prestações de serviço é essencial para que o Poder Público não se utilize a ilegalidade como mecanismo de enriquecimento.
\end{abstract}

Palavras-Chave: ICMS; Fenômeno da Repercussão; Consumidor.

\section{Introdução}

Consoante o Artigo 155, inciso II da Constituição da República Federativa do Brasil:

Art. 155. Compete aos Estados e ao Distrito Federal instituir impostos sobre:

[...]

II- operações relativas à circulação de mercadorias e sobre prestações de serviços de transportes interestadual e intermunicipal e de comunicação, ainda que as operações e prestações se iniciem no exterior;

0 Texto constitucional vigente conserva características essenciais do ICM (imposto sobre operações relativas à circulação de mercadorias) previsto em legislação anterior, no entanto, foi incluída na hipótese tributária a prestação de serviços de transporte interestadual, intermunicipal e de comunicação. Também passou a abranger imposto sobre energia elétrica, combustíveis e minerais (BASTOS, 2002, p. 380).

Não obstante estejam reunidos no dispositivo constitucional supratranscrito impostos inconfundíveis entre si (prestação de serviços e circulação de mercadorias), o fato de estarem submetidos ao princípio da não cumulatividade permite a coerência de um estudo simultâneo (CARRAZA, 2003, p. 35).

\footnotetext{
${ }^{1}$ Graduada em Direito pela Universidade Estadual de Londrina.

${ }^{2}$ Graduada em Direito pela Universidade Estadual de Londrina.
} 
A Carta Magna, em seu Artigo $155, \S 2^{\circ}$, conferiu a Lei Complementar estabelecer normas gerais sobre o ICMS. Deste ditame adveio a Lei n. 87/96, que impôs as diretrizes voltadas ao legislador estadual.

No Estado do Paraná a Lei 11.580/1996 regula o ICMS, sendo mesma sujeita a constantes modificações.

Em relação ao Imposto sobre circulação de mercadorias, destaca-se que o seu critério material, segundo a doutrina majoritária, se implementa com a circulação econômica, isso significa que mesmo que um produto seja transferido entre dois estabelecimentos pertencentes a uma mesma empresa, o referido imposto é devido, pois o princípio da não cumulatividade impede a ocorrência de prejuízos mercantis (MACHADO, 2004, p. 358-359).

Ocorre que independentemente da circulação ser considerada econômica ou jurídica (entendimento que defende que circulação somente se efetiva entre estabelecimentos de titulares diversos), o valor respectivo é embutido no preço final do produto. Conseqüentemente o consumidor torna-se o contribuinte de fato da arrecadação estatal, sem que ao menos tenha disponíveis mecanismos que permitam o acesso a esta informação.

Ainda que arque com o montante pecuniário, caso ocorra uma cobrança indevida de ICMS, o consumidor não é parte legítima para pleitear a restituição respectiva, uma vez que o mesmo não é contribuinte de direito.

Intrigante ressaltar, que neste caso, o sujeito passivo do ICMS (contribuinte de direito) também é ilegítimo processualmente, pois de fato, o valor foi embutido ao produto e repassado ao consumidor.

A impossibilidade ou os entraves aparentemente intransponíveis, da restituição de ICMS cobrado indevidamente, fomenta no mínimo, questionamentos quanto à compatibilidade das conseqüências do fenômeno da repercussão atinentes a repetição indébito e os ditames previstos na Carta Maior de 1988. 


\section{Contribuinte de direito e contribuinte de fato}

O contribuinte de direito, o responsável tributário, o substituto tributário e aquele que arca com o montante financeiro atinente ao ICMS (contribuinte de fato) são inconfundíveis.

Tanto o contribuinte de direito como o responsável e substituto tributário são sujeitos passivos da obrigação tributária. Todos recolherão o ICMS, mas não o suportarão de fato.

O encargo tributário será repassado para o consumidor mediante o ICM S embutido no valor das mercadorias, denominado como ICMS "por dentro":

0 art. $13, \S 1^{\circ}$, I, da Lei Complementar $n^{\circ} .87 / 96$, reprisando disposição de lei complementar anterior (DL $\mathrm{n}^{\circ}$.406/68), estabelece que 0 montante do ICMS integra a própria base de cálculo, fenômeno que se dá o nome de ICMS "por dentro".

Isso porque quando verificamos o preço de um produto na prateleira de um supermercado, devemos enxergar nele a soma de vários "preços" compondo o preço final. Refiro-me às despesas várias que o comerciante tem com o produto a ser comercializado: funcionários, manutenção do local, aluguel, seguros etc. Além disso deve-se embutir no preço final o lucro e, fundamentalmente, os impostos. Aí se vê o ICM S "por dentro", já calculado pelo comerciante (SABBAG, 2007, p. 362).

0 contribuinte de direito é aquele que realiza o critério material da hipótese tributária. Segundo a regra do art. 155, II, CF/88, são contribuintes de direito os que praticam operações relativas à circulação de mercadorias; prestam serviço de transporte intermunicipal e interestadual ou prestam serviço de comunicação.

Quando constar outro sujeito passivo na relação jurídica tributária, estar-se-á diante do substituto ou responsável tributário ${ }^{3}$.

Na substituição, o legislador afasta por completo o verdadeiro contribuinte, ou seja, aquele que realiza 0 critério material, sendo previsto legalmente 0 encargo a uma outra pessoa (substituto), que fica obrigada a pagar a dívida respectiva (MELO, 2004, p. 155).

No imposto em tela há a substituição regressiva (para trás) e a progressiva (para frente). Na substituição regressiva a lei atribui a responsabilidade ao adquirente de uma

\footnotetext{
${ }^{3}$ Não pode olvidar-se a hipótese da relação jurídica ser composta por sujeito que não realizou o critério material da norma tributária. Como ocorre no caso em que lei incumbe a outra pessoa o recolhimento do ICMS, como forma de sanção em decorrência de uma antijuridicidade. Cite-se o caso de sujeição do depositário ao tributo referente às mercadorias depositadas sem nota fiscal (MELO, 2004, p. 154).
} 
determinada mercadoria, por razões de comodidade, praticidade ou pela circunstância do real contribuinte não manter organização adequada de seus negócios. ${ }^{4}$ (M ELO, 2004, p.156).

$\mathrm{Na}$ substituição progressiva o legislador indica uma pessoa responsável pelo recolhimento de um determinado valor (tributo) sobre um fato futuro e incerto. (MELO, 2004, p. 156). Esta é a chamada substituição tributária "para frente".

\section{0 fenômeno da repercussão}

É o fenômeno econômico que permite passar ao consumidor todo o custo da atividade econômica (JULANO, 2002, p.4).

Trata-se do fenômeno de transferência de encargos, nos tributos indiretos, como 0 ICMS ou o IPI, isto é, o ônus tributacional repercute sobre o ocupante da fase seguinte de uma operação plurifásica, não sendo assumido por aquele que deu ensejo à circulação originária. A repercussão e a passagem do ônus tributacional ao contribuinte de fato, não recaindo sobre o contribuinte de direito (SABBAG, 2007, p.46).

Assim, os valores pagos de ICMS pelo contribuinte de direito são repassados para 0 consumidor final, que, em realidade, arcará com toda a carga tributária.

\section{Conceito de consumidor}

O consumidor, sob o ponto de vista econômico, pode ser considerado todo aquele destinatário final do produto, independente de ser ou não adquirente, produtor ou não dos bens (FILOMENO, 2004, p. 34). Visto sob este aspecto, podem ser considerados consumidores todos aqueles que necessitam de terceiros para a obtenção de bens ou prestações de serviços (CARVALHO, 1997, p. 21).

O conceito psicológico não leva em consideração a ordem política, ou ideológica. Sob este âmbito, consumidor pode ser considerado como [...] o sujeito sobre osquais se estudam as reações a fim de se individualizar os critérios para a produção e motivações internas que se levam ao consumo. 0 aspecto psicológico interessa diretamente a ciência do marketing (FILOM ENO, 2004, p.34).

\footnotetext{
${ }^{4}$ Nas operações de sucata é comum exigir-se o ICMS em etapa posterior, em lugar do próprio sucateiro (contribuinte). É o fenômeno do diferimento (postergação de exigência tributária para momento ulterior do ciclo mercantil) (MELO, 2004, p.156).
} 
Sob o ponto de vista sociológico pode ser definido como qualquer sujeito que desfruta de bens ou serviços, sendo pertencente a determinada classe social. Na concepção literária e filosófica o termo consumidor e associado a valores ideológicos mais predominantes. A palavra e vinculada a sociedade de consumo ou consumismo (FILOMENO, 2004, 35)

A conceituação literal compatibiliza-se mais adequadamente a concepção de consumidor no aspecto econômico jurídico:

Consumidor é qualquer pessoa, natural, ou jurídica, que contrata para a sua utilização, a aquisição de mercadoria ou prestação de serviços, independente do modo de manifestação da vontade, isto é, sem forma especial, salvo quando a lei exigir (FILOM ENO, 2004, P.35)

Segundo Filomeno (2004, p. 39) pode-se entender a concepção jurídica de consumidor:

Qualquer pessoa física, que isolada ou coletivamente, contrate o consumo final, em beneficio próprio ou de outrem a aquisição ou a locação de bens.

O Artigo 2 do Código de Defesa do Consumidor estabelece que consumidor e toda pessoa física ou jurídica que utiliza e adquire produtos como destinatária final ${ }^{5}$.

O parágrafo único do mesmo Artigo equipara os consumidores a coletividade de pessoas, ainda que indetermináveis, que haja intervindo nas relações de consumo. Nesse dispositivo, o intuito e por a disposição a universalidade ou grupo de consumidores relacionados a um determinado serviço, instrumentos processuais para a devida reparação (FILOM ENO, 2004, p. 50).

\section{0 fenômeno da repercussão e o consumidor}

A Repercussão é um fenômeno econômico ainda não solucionado pelo direito, uma vez que o contribuinte de fato não pode pedir restituição do valor pago pelo tributo, pois não figura como pólo passivo da relação jurídica tributária.

\footnotetext{
${ }^{5}$ De acordo com Lucca (1995, p. 40), para verificar-se se a pessoa jurídica e consumidora, não se deve averiguar se a mesma se trata de destinatária final, mas sim a sua vulnerabilidade em relação ao fornecedor.
} 
Quando um tributo é cobrado indevidamente, onera o custo da atividade econômica suportada pelo consumidor, que não compõe nenhum dos pólos da relação jurídica tributária, logo, não pode pedir a restituição pertinente, favorecendo enriquecimento incompatível com os pilares do ordenamento jurídico estatuído em 1988.

Em Relação ao contribuinte de direito, este só pode requerer administrativamente ou judicialmente a restituição do tributo se demonstrar que assumiu diretamente o encargo do ICM S, essa é a interpretação do STF consubstanciada na Súmula 546:

546. Cabe a restituição do tributo pago indevidamente, quando reconhecido por decisão que o contribuinte jure não recuperou do contribuinte de facto o quantum respectivo.

Esse entendimento não ameniza a complexidade da questão, sendo ainda muitos os obstáculos para a restituição do valor devido. 0 contribuinte de fato deverá provar que não inseriu o preço no produto, ou caso contrário deverá obter a autorização do contribuinte de fato para pleitear o ressarcimento:

Assim, se tratando de tributo qualificado como da espécie indireta, o contribuinte de jure deve provar, por seus livros e arquivos, que não agregou o tributo ao preço, ou se o agregou, que está autorizado pelo contribuinte de fato a receber a restituição. Pode, ainda, demonstrar a impossibilidade prática da transferência, nas circunstancias especiais do caso concreto (BALEIRO apud CAIS, 2007, p. 429).

São patentes as dificuldades circunstanciais que cercam a possibilidade de restituição do ICM S arrecadado indevidamente pelo Poder Público.

\section{A incompatibilidade dos obstáculos da restituição do ICMS com a ordem constitucional vigente e a necessidade de acesso a informação}

0 repasse dos valores do ICMS ao consumidor, impedindo que o mesmo obtenha informações que permitam 0 acesso ao valor embutido no produto, bem como a impossibilidade de restituição do montante pago indevidamente, viola a Constituição Federal. 
Mostra-se claro o antagonismo destes fatos em relação ao compromisso que a Lei Maior incumbiu ao Estado como protetor dos direitos dos consumidores, bem como 0 princípio do acesso ao Poder Judiciário:

Art. 50 Todos são iguais perante a lei, sem distinção de qualquer natureza, garantindo-se aos brasileiros e aos estrangeiros residentes no País a inviolabilidade do direito à vida, à liberdade, à igualdade, à segurança e à propriedade, nos termos seguintes:

$[\ldots]$

XXXII - o Estado promoverá, na forma da lei, a defesa do consumidor;

$[\ldots]$ XXXV - a lei não excluirá da apreciação do Poder Judiciário lesão ou ameaça a direito;

Salienta-se ainda que a defesa do consumidor constitui em princípio da ordem econômica, consoante aos ditames do artigo 170 da Carta Magna:

Art. 170. A ordem econômica, fundada na valorização do trabalho humano e na livre iniciativa, tem por fim assegurar a todos existência digna, conforme os ditames da justiça social, observados os seguintes princípios:

$[\ldots]$

$\mathrm{V}$ - defesa do consumidor;

Evidente, portanto, que a atual situação do consumidor perante o fenômeno da repercussão não se coaduna com um Estado Democrático de Direito.

A necessidade de fornecer informações relativas ao ICMS do Consumidor foi reconhecida pela Constituição Federal, no seu artigo 150, § 50:

Art. 150. Sem prejuízo de outras garantias asseguradas ao contribuinte, é vedado à União, aos Estados, ao Distrito Federal e aos M unicípios:

[...]

§ 5 o A lei determinará medidas para que os consumidores sejam esclarecidos acerca dos impostos que incidam sobre mercadorias e serviços.

Faz-se urgente à concretização desse escopo constitucional, uma vez que somente desta forma pode-se efetivar a conscientização dos consumidores referente às arrecadações estatais, bem como os direitos dos administrados de exigirem a transparência do Poder Público. 


\section{Conclusão}

Verifica-se que os requisitos da legitimidade processual atinente ao pleito de restituição de ICM S possuem empecilhos que favorecem a arrecadação indevida.

O consumidor, não obstante arque com os custos decorrentes do fenômeno da repercussão, não pode recorrer ao Judiciário, uma vez que carece de legitimidade processual.

Por outro ângulo, a obtenção da restituição pelo contribuinte de direito se condiciona (quando não comprovar que deixou de inserir o ICMS no produto ou serviço) ao consentimento do contribuinte de fato, sendo obviamente, dificultosa a sua obtenção devido ao número de produtos e clientes.

A desconsideração dos custos sofridos pelo consumidor no ato de aquisição de um produto onerado por um imposto indevido, demonstra-se como afronta ao Estado Democrático de Direito.

Diante deste impasse faz-se necessária à concretização da disposição prevista no Artigo 150, §50 da Constituição Federal.

Para fortalecer um Estado nos pilares mais essenciais da democracia, os privilégios sejam distribuídos a todos, bem como os encargos, que não devem ser suportados por alguns, tal como ocorre com fenômeno da repercussão no ICM S.

\section{Referências}

BASTOS, Celso Ribeiro. Curso de Direito Financeiro e Tributário. 9. ed. São Paulo: Celso Bastos, 2002.

BRASIL. Código de Defesa do Consumidor. Lei n. 8.078, de 11 de setembro de 1990. Diário Oficial, Brasília, DF, 11 de set, 1990.

BRASIL. Constituição (1988). Constituição da República Federativa do Brasil. Brasília, DF, 1988

CAIS, Cleide Previtalli. O processo tributário. 5. ed. São Paulo: Revista dos Tribunais, 2007.

CARRAZZA, Roque Antonio. ICM S. São Paulo: Malheiros, 2003.

CARVALHO, M iriam Regina de. Direitos do consumidor em face de nova legislação. São Paulo: Direito, 1997. 
FABIAN, Christop. 0 dever de informar no direito civil. São Paulo: Revista dos Tribunais, 2002.

FILOM ENO, José Geraldo Brito. Manual de Direitos do Consumidor. 7. ed. São Paulo: Atlas, 2004.

GRINOVER, Ada Pellegrini et al. Código Brasileiro de defesa do consumidor comentado pelos autores do anteprojeto. 8. ed. Rio de Janeiro: Forense, 2005.

JULIANO, Denézio. ICM S: a substituição tributária "para frente". Monografia. UEL. Londrina, 2002.

LUCCA, Newton de. Direito de consumidor: aspectos práticos perguntas e respostas. São Paulo: Saraiva, 1995. v. 10.

M ELO, José Eduardo Soares. ICM S: teoria e prática. 7. ed. São Paulo: Dialética, 2004.

SABBAG, Eduardo Moraes. Elementos do direito. 8. ed. São Paulo: Premier, 2007. 